\title{
Effective Leadership in Organizations: African Ethics and Corruption
}

\author{
Angelo Nicolaides ${ }^{1}$, King Carl Tornam Duho ${ }^{2}$ \\ ${ }^{1}$ Graduate School of Business Leadership, University of South Africa, Pretoria, South Africa \\ ${ }^{2}$ University of Ghana Business School, Accra, Ghana \\ Email: nicola@unisa.ac.za, kctduho@st.ug.edu.gh
}

How to cite this paper: Nicolaides, A. and Duho, K.C.T. (2019) Effective Leadership in Organizations: African Ethics and Corruption. Modern Economy, 10, 1713-1743. https://doi.org/10.4236/me.2019.107111

Received: February 15, 2019

Accepted: July 13, 2019

Published: July 16, 2019

Copyright $\odot 2019$ by author(s) and Scientific Research Publishing Inc. This work is licensed under the Creative Commons Attribution-NonCommercial International License (CC BY-NC 4.0). http://creativecommons.org/licenses/by-nc/4.0/ (c) (i) \& Open Access

\begin{abstract}
There is much evidence to support the notion that inspirational leadership is inextricably crucial for the functioning of any organization, either in the private or public sector, which is bent on operating as a goal-oriented body within which various individuals work under the coordination of an ethically oriented leader. The paper unpacks African Ethics and how a loss of virtue in leadership in both the public and private sectors, has led to corruption with its hugely negative impacts on society. The paper highlights theoretical conceptions and potential practical actualizations of ethical practice. Recommendations and suggestions are made as to what can be done to mitigate unethical practices such as corruption with its corrosive effect on life in general.
\end{abstract}

\section{Keywords}

Corruption, Ubuntu, Leadership, Virtue, Africa

\section{Introduction}

This article contemplates apposite literature on ethical business practice, corporate governance, stakeholder engagement, value maximisation and sustained business performance. An in-depth examination of relevant literature and a narrative review was conducted to explicate both primary and secondary sources including books, research reports, journal articles, magazines, conference papers and various internet materials. The researchers examined various theories and frameworks available on business ethics, governance and stakeholder engagement and the value maximisation in order to obtain an enhanced understanding of the impact of these aspects on a company's sustained performance and growth. A holistic understanding is offered underwritten by prevailing theories, so as to promote ethical quality driven business practices. Use was thus made of current 
literature from mainly secondary sources on corporate governance, ethics and stakeholder engagement in order to guide companies to adopt sustainable practises when dealing with all stakeholders. This is needed since many public and private entities have unethical cultures.

Ethics is generally a collection of principles or standards of expected human conduct that govern the behaviour and guide the decision making of all individuals as well as groupings of people's [1]. Irrespective of whether the origin of ethics is African or western in orientation it arises from human nature itself, and is a natural body of laws that must be adhered to by employees and other stakeholders of an organization and by societal members in general. Many consider ethics to be a normative science because it is concerned with the norms of human conduct that are actually far more than a mere collection of values, and it is an operational dimension all organizations need. An organization and a society need to consider ethics if they wish to be sustainable. Adam Smith, the author of The Theory of Moral Sentiment, states that one cannot say they are human without having a moral sense [2].

In order to develop my argument of an understanding of the importance of ethical leadership, it is worthwhile pondering ethics per se. All individuals are products of particular societal structures and systems and owe a great deal of their identity to the community in which they live. Ethics is therefore a complex philosophy because of the moral aspects which are a mixture of tradition that they receive and it is often founded on the personal opinions of people. Individuals living in the western Christian world base their ethical beliefs and their behaviour on the Decalogue (Ten Commandments') that were handed to Moses on Mount Sinai. Ethics is then a series of laws and principles that individuals should try to live by. So, there is then a deep connection between ethics and the Abrahamic religions' Holy Scriptures of Judaism Islam and Christianity and also the ethics of great western philosophers, predominantly from Classical Greece.

When considering ethics, we often make assumptions about human nature and the idea that humanity is born into original sin and in need of redemption, which is of course, in opposition to the romantic view which assumes that humanity is programmed to be good. In Hinduism and Islam, we also encounter universal principles of ethics which are compatible with western ethics and in some instances these may be more stringent and austere than in the western modality.

Leadership is defined as "any behaviour that influences the actions and attitudes of followers to achieve certain results" [3]. Leadership then has an important role to play in all stages of an organization's lifetime in imparting organizational values which are usually in evidence in a code of ethics or conduct, and also in the mission and vision of the organization. Clearly, the personal values of a leader and those who come after him or her, need to be carefully assimilated into the culture of the organization [4]. All organizational activity should be synonymous with the notion of ethical value creation and this should be com- 
municated to stakeholders. An operative and regular transparent communication with stakeholders emphasizing ethics will serve as an important interface between how leaders drive organizational undertakings and societal interests at large [1]. Ethics and public service principles are essentially the "body and soul" of public administration [5] and ethical principles should equally pervade all organisations. In the African world-view the principle which guides leadership decision-making processes is referred to as ubuntu (humaneness). Ubuntu encapsulates the essence of what it means to be human being. Leaders espousing this philosophy try to treat all people with respect and embrace universal brotherhood and seek the wellbeing of all people.

The arrival of the Fourth Industrial Revolution has provided a means for stakeholders and pressure groups to observe an organisation and its leader's actions. This encourages organisations to be more ethically and socially conscious. At any rate, organisations which are ostensibly more ethically responsible than others which are less so, are able to strengthen their brand and augment their organisational performance. Within this context, Koslowski [6] states that culture plays a key role in the attitude of a leader towards management: "In the interaction between philosophy and management, there are three central fields: management ethics, the cultural philosophy of management and of management culture, and the ontology and epistemology of management and management theory, the philosophy of science of management" [6]. African society is constantly plagued by huge challenges in unethical practice and corruption and requires somewhat of a new ethical vision and culture [7].

Modern-day African leaders live and lead in a global village in which the dominant modes of leadership were to a large extent inherited during the period of colonialism.

Leaders in Africa as is the case on other continents, whether they be operating in the public or private domains, make a critical difference to the success or failure of the organisations they steer, across the entire range of existence. While it may be true to suggest that certain leadership principles are relevant universally, and that African leaders can learn from the experiences of the rest of the world, we should not forget that Africa also has much to impart to the world in the sphere of right conduct. Leadership in Africa needs to "get back to its roots" and adopt relevant practices based on what have become neglected African cultural traditions. African leaders in the main have lost a wilful ability to do the right things, and doing right things is essentially something so fundamental to African ethical belief. Deloitte \& Touche in a 2007 survey assert that leaders in organisations play focal roles in establishing the workplace climate [8]. Nonetheless, what is important to note is that leadership is increasingly based on personal integrity, and stewardship including partnership and empowerment, and an end to paternalism [9]. It is perhaps opportune to quote Alexander Solzhenitsyn who stated: "It is not because the truth is too difficult to see that we make mistakes. It may even lie on the surface; but we make mistakes because the easiest and most 
comfortable course for us is to seek insight where it accords with our emotions-especially selfish ones" [10].

\section{African Ethics}

In African societies, the values generally espoused are those which align with the values of the local community as a set of commonly understood moral principles and assumptions which are grounded on realistic and logical judgments of what moral conduct entails. Gyekye [11] refers to African ethics as those which "refer both to the moral beliefs and presuppositions of the sub-Saharan African people and the philosophical clarification and interpretation of those beliefs and presuppositions".

The roots of African Life, culture and value systems in Southern Africa in particular are found in the philosophy of ubuntu but they have also been influenced by especially the Judaeo-Christian tradition. Ubuntu is considered to be a divinely inspired action and it permits Africans to operate according to socio-cultural norms and values which are founded on the reality of one's inner being [12].

Both ubuntu and Christianity call for caring for others and for upholding moral integrity, and it is only through others that a person can be considered to be a human being and participation is then important. In this context, all people need to be treated inclusively and have their suggestions and ideas considered, and above all, they should be treated with human dignity. African society develops its ethics based on customs and on what is deemed to be moral or immoral by various cultures. An ethical action in Africa, is one which is considered to be the ideal one by society [13]. African societies afford the family the utmost status and it is families that are considered to be the most appropriate models relating to the concept of community [14]. Ubuntu emphasises that the greatest goodness should be created for the greatest number of people and the notion of ethics is evaluated as a duty and not as a right, and so human welfare is stressed first and foremost [15].

The African philosophy therefore has its foundation on democratic ideals and welcomes consultation and inclusivity from all role-players from all walks of life, and this can be translated into any organization's strategy. Consequently, the development of practices, policies, procedures and processes must all be aimed at developing people in the institutions they serve [16]. Ubuntu is compatible with a number of ethical theories including the common good approach, the utilitarian approach, the rights ethical or deontological approach, the justice or fairness approach and the virtue approach. The greatest similarity is however, with the common good approach which is promoted universally in a range of common values and moral or ethical principles that exist in most societies. Fundamentally then, societies across the world commonly share what are deemed to be positive and negative values. Charity starts with the family first and foremost, and basically reveals the primary nature of God's presence within people [17].

To deny a family member Ubuntul Botho is considered to be a highly immoral 
act [18]. African Society consequently embraces communalisation and all human life has a strong community association. This is the antithesis in the western paradigm in which human beings are urged to act independently and thus as separate entities which are free to act as they wish irrespective of the damage they may cause both to themselves and also to society. Yawson [19] states that Ubuntu is a substitute to a diverse approach of leadership which is an Afrocentric leadership style which is the principal mandatory style of leadership in Africa. This has however not been empirically tested. Whether it exists in practice is debatable given that corruption is either visible or hidden in Africa as needed policies are often neglected by politicians due to their focus on making more money, inspired by an ethic of self-preservation at the expense of others [20].

For most Africans, freedom exists in an assortment of privileges and exclusions that derive from the notion of collective life and how one tends to handle their responsibilities as members of the community at large. It is important for us to understand the nuances of African ethics since it is these distinctions that should be reflected in leadership decision-making processes where the notion of collective management is of paramount importance.

Effective and virtuous leadership is at the heart of every effective organization. It follows that effective leaders are those who are inspirational role models of virtue, and ethical and moral leadership. Ubuntu views leadership as a moral service including a transformational element in which people should be true to themselves and strive to exist in truth and sincerity, and be devoid of pretence and narcissistic preoccupation with their egos'. Leaders also need to have vision and be forward thinking in how they lead and value the interconnectedness they share with society. Good leaders invariably tend to project honesty and reliability and are bent on promoting and supporting an environment in which ethical practice is second nature.

In the African context, the values that should be espoused by leaders include legitimacy in a role, the desire to develop a group and promote the growth of individuals, a community focus, joint decision making in a spirit of sharing values, the promotion of dignity and respect in the culture of an organisation and in its climate, diversity and management and the sharing of values in an environment where solidarity is evident [21].

Nowadays, leaders cannot so easily manipulate their organisations and as such leadership is not considered to be sacrosanct anymore and it is increasingly called to account [9]. It is interesting to note that early literature has spoken to acts of compliance where individuals often behave in a manner that is consistent with organisational norms and values, despite having personal values and beliefs that are at a variance with such desired behaviours [22]. Nonetheless, many other leaders neglect their moral leadership role as they find it difficult to define a universal set of ethical principles and values. Numerous politicians representing the public falter in terms of unethical conduct, in for example handling of contracts or agreements, this is indeed a serious misdemeanor and the obligations of 
public servants in discharging their duties are thus flaunted [20]. Individuals basically tend to frame their understanding of values from their own personal experiences, philosophy or religions [23] and it's not entirely possible for all employees to have a common perception of what is moral and what is ethical. This makes it even more important for leaders to consider societal rules and laws and what is ultimately considered to be appropriate behaviour at any given time and in a particular environment.

For our purposes, ethical behaviour occurs when an individual or organization does what is good for others in society and there is principles decision making and behaviour in the interaction that takes place. One cannot on the other hand fail to take his or her self-interest into consideration. Leaders can thus be focused on themselves but should not only be self-serving in what they do. In the public and private sectors, managers need to be transparent in their dealings and held accountable for carrying out a defined set of duties or tasks, and in conforming with regulations, rules and standards applicable to their functions [24].

Ethics and morally right conduct are very closely integrated with a wide range of global issues of basic human rights and conduct. Organizations require effective and strong leaders who support ethical conduct especially given that the world has a plethora of socio economic problems, many of which are the direct result of greed which leads to bribery and corruption. Society expects leaders whether they be in the private or public sector to adhere to high standards of ethical behaviour and in addition there are increasingly important governmental regulations in place for all organizations and their activities to remain ethical.

When decisions are taken by those in authority, these are expected to benefit the entire collective corpus under the spirit of ubuntu. However, while there are communitarian and individualistic cultures, in essence all decisions taken seek in some or other manner, to ultimately advance the interests of some individuals [25]. It is evident from daily media reports that leaders tend to act in their greedy self-interest when what are considered imperatives to have, and usually financial incentives, appear. The literature advises that leaders at higher levels of ethical development are far less likely to make questionable decisions and choices [6] [11] [13] [26].

Mathooko [15] states that supererogation or acting "beyond the call of duty" is an important influence on African leadership. Leaders need to acknowledge that it is their responsibility, by virtue of their positions, to inculcate in the organisational DNA, the importance of ethical conduct and that they are also expected to serve as role models for those whom they lead. Leaders should thus strive to create an ambience in their organizations in which ethical conduct is exuded throughout the entire workplace as well as in all the systems and processes that are in place [27] [28].

The mission statement of all organisations, as well as their vision, must speak to a culture which is intolerant of any corrupt practices, and endeavour to en- 
dorse ethical practice in the organisations role in the social order. African moral compassion must be extended to all peoples, irrespective of their cultural background or society [15].

Either way, greed and self-centredness and especially the ethic of self-preservation are huge hurdles for leaders to cross. Nonetheless it is important to adopt a common set of values for an organization and incorporate these into a code of conduct or a credo for use by the organisation [29] [30]. When it comes to value systems no situation can be adequately transformed unless there are totally transformed individuals driving the situation. It is ultimately the people who create the spirit of ethical behaviour in an organization which makes it possible to nurture new practices and ultimately to even sustain them [31]. An ethics-based culture in any organisation is vital in attracting a good reputation and ultimately success in areas such as gaining trust and stakeholder buy-in [32].

Organisations are expected from time to time, to re-evaluate their systems and processes as well as their structures, since these clearly influence the ethics and leadership style which exists within their walls. In South Africa, laws have been promulgated to endorse integrity. The South African Public Service Commission (PSC) is the champion for upholding integrity in the Public Service via its Code of Conduct which offers carefully crafted guidelines on expected ethical conduct [33]. Unfortunately it has not yielded the expected results since ethical behaviour frequently has to do with merging interests with the moral principles behind the choices made.

Any choices people fundamentally make reveal whether they are either "good" or "bad", and whether what they ultimately decide will be harmful in one way or another [34].

The dawn of globalization and the Fourth Industrial Revolution, coupled with the increasingly consumerist and hyper-materialistic driven society, has led to a proliferation of hitherto unfamiliar ethical concerns when it comes to leadership in organizations. The Fourth Industrial Revolution is synonymous with unexplored development in digitization and internet connectivity. "The ICT sector, industry and governments have a responsibility to unlock its potential for citizen service delivery, customer experience and innovative solutions, for a better life for all... entire systems of production, management and governance are being affected" [35].

It thus increasingly has the potential to drive Africa forward, empowering innovation, prompting new business models and improving the [ethical] delivery of public services [35] many of which have been enriching a cadre of corrupt officials under a western paradigm. This is one reason as to why many African philosophers are disparaging when it comes to the western paradigm of what it essentially means to be human. They abhor exclusively commercially oriented mentalities, egotistical competitiveness and unrestrained individualism which they consider to be bereft of moral value and common sagacity [36]. Behaviour which is in line with the narcissistic value system that is prevalent in the west 
and which is based on the ethic of self-preservation is not conducive to effective leadership and yet such practice is rife. Conduct which strays from the moral imperatives governing the behaviour of individuals and businesses is deemed to be unethical as it intends to destabilise a principled system in which an organization operates. The ethic of self-preservation (ESP) is highly destructive in the long-term this is primarily because one needs to consider the needs of all stakeholders in society. The unethical behaviour of public officials has clearly led to the formation of highly deleterious perceptions about the Public Service in general. Thabo Mbeki, the President of South Africa in 2006, upheld the notion that corruption is a huge hindrance to the country's efforts in alleviating dire poverty. Furthermore, it hampers economic development while simultaneously breaking down the social fabric of society [20].

The western paradigm places stress on rational and systematic thought and a leader's role is formal and he or she belongs to an organisation that exhibits authority and power through hierarchical structures. There are rigid rules of engagement and leaders have deliverable targets to reach [37]. African leaders however, have their authority based on a spirit of compromise within a group so that there is consultation and consensus and a leader's goals are highly flexible. It is thus expected that African leaders be somewhat visionary, self-controlled and self-reflective as they carry out a mandate to improve the lot of others [37].

The spirit of ubuntu is contrary to the erosion of communal values by unprincipled leaders. When unethical leaders furtively procure any assets, special privileges or advantages, those who serve under them invariably tend to become disloyal to them or the organization in which they serve [23]. African ethics focuses not only on rights but especially on one's duty when it comes to considering the welfare of others. The rights of all stakeholders, both as individuals and also as a collective, needs to be treated in an ethical manner [38]. It is most unfortunate that when the rules of conduct are unclear, it is likely that individuals could be attracted to yield to dishonest behaviour for personal immoral gain.

\section{Virtue in Leadership and Leadership Style Choices}

What does it take to be a leader? Leaders should seek the happiness of all stakeholders (eudaimonia) from a noticeably ethical perspective. In his Nicomachean Ethics, (ca. 325 B.C.), Aristotle asks: "what is the good of man?" and he responds by saying it is an activity of the soul which conforms with virtue. By virtue, he refers to inter alia kindness, generosity, courage, benevolence, fairness, tolerance, patience, prudence, honesty, dependability, self-discipline, and passion, justice, loyalty, stability civility and thoughtfulness. Aristotle referred to ethos, pathos, and $\log o s$ as a guide. By ethos he denotes one's moral character as the basis of one's ability to influence others. Pathos refers to one's ability to evoke emotional states in others and change their perspectives, while $\log o s$ is one's ability to provide dependable motives for taking a particular action. Where there is a Phronesis, this associates ethics and actions and wisdom is evident in any decisions 
made by people.

While a number of theories have been developed relating to the rightness or wrongness of one's actions and how one is obliged to do some things [39] there is growing unethicality in organizational behaviour. Theories such as, for example, utilitarianism, which suggests that one should do whatever leads to the general happiness, or ethical egoism which posits that every person should do what promotes the personal interests are inadequate to stem greed. In addition, there is the Social Contract theory which asserted that it is correct for one to follow the rules that are rational, and which self-interested individuals would mutually agree to follow for their benefit but this too is inadequate to stem moral breakdown. Kant also suggested that we need to follow rules that we accept to be universally applicable and in all circumstances [39], but such rules are broken at will. Despite these different theories, moral philosophy is not satisfying the need relating to virtuous ethical conduct. It is suggested that humanity should return to an Aristotelian way of thinking in which the virtues prevail [40]. When one is on the journey of becoming a leader with integrity, the path is fraught with dilemmas and challenges which need to be surmounted if one is to succeed [41].

These aspects raise essential questions as to how leaders reach their daily decisions and about their skills in leading. There is however a distressing dissociation of leadership from honest authority, due to the materialistic and narcissistic spirit that pervades the contemporary organization. What is missing then, is authority that is entrenched in virtue, truth and in seeking universal happiness. There are also cases of several leaders who are considered to be virtuous failing in their tasks as they tend to operate by trial and error and they are usually uncertain as to which leadership style they should adopt. The real leader selects an appropriate style(s) of leading and they develop a strategic vision based on ethical practices which meet the needs of others, and also those of the organisation which they serve. The effective leader motivates employees towards innovative moral action [42] and evaluates ethical issues from a variety of strategic management perspectives [43].

Decency and virtuous actions are increasingly being overlooked in many organizations. Seligman [44], who is a proponent of the developing field of Positive Psychology, states that virtually all psychological research conducted in the five decades before the millennium focused mainly on human dysfunction, rather than the positive virtuous aspects of what it takes to be an eudaimonic person. The reality is that true leadership must be anchored in authority, as this is the only way to spare it from despotism. We should however be careful not confuse authority with authoritarianism.

Authority, is in real terms generally a trustworthy position and from an Aristotelian as well as an Ubuntu perspective, and one attains a position of authority because as he or she is suitably qualified for it not through nepotism. In each of these it is from a superior ethical spiritual being from which authority is derived. Authority and truth go hand in hand. A leader thus needs to be a truthful hu- 
man being and select a style of leadership that is conducive to sustainability and societal approval. Forde, Hobby and Lees [45] have defined a leadership style as being "the habitual approaches employed by an individual to stimulate and subsequently steer employees". Given that leaders greatly influence the organisational climate, business ethics should be firmly ingrained into the organisational ethos by them. Those serving in the public sector have a number of expected obligations including inter alia, respecting the procedures that give credence to the actions of public officials and legitimate them, serving the public interest first and foremost, and respecting colleagues and subordinates and dealing honestly, and with integrity and fairness [46].

Irrespective of the setting, whether in the public or private sectors, a leader then has access to different styles of leadership to select from such as the authoritarian, democratic/participative, laissez faire/free reign, and charismatic style in which the leader motivates others with energy and belief and a pure presence which builds morale and employee drive. In our context, the transformational leadership style is needed, in which radical change is required, and when the future is not so certain, and when there is a need for fresh ideas and innovative approaches to doing things. The emphasis must be on assuring that leaders make decisions and select actions that serve organizational and societal goals rather than their own self-serving interests. Goleman [47] refers to six leadership styles that can be used alternately or in a flexible fashion to influence an organisation's climate positively so as to result in organisational sustainability. He also asserts that leadership style is critically important in elevating organisational performance and efficiency. Leaders with a good understanding of diverse styles of leadership are more effective than those who depend on coercive and oppressive styles of leading [47]. Yukl et al. [48] [49] states that the keys ethical leadership in terms of principles required are honesty and integrity, ethical behaviour, fairness in decision making and a spirit exuding kindness and compassion.

There are several guidelines proposed by Gichure [50] on the professed aim of business activities within an organisation and these may serve as a basis for dealing with all there levant stakeholders from an ethical standpoint. Gichure [50] stresses that: "Africa ought to develop its own management and leadership system based on the spirit of Ubuntu." Leaders need to be made to understand that an ethical stance pays off in many ways and more especially leads to sustainability which is why ethical values must be internalized so as to endure in the organizational DNA [51]. Aristotle stressed that virtues as character traits should be manifested habitually and unchangeably so it is important that primary values be continuously applied and this, to a certain degree, depends on the succeeding cohort of leaders and how they embrace what was affected by their predecessors [52]. If we consider one of virtue, for example honesty, it becomes abundantly clear that civilisation cannot succeed without people communicating honestly with one another [39]. Without virtuous people civilization is not sustainable. We could argue that different societies give virtues different interpreta- 
tions of and that character traits vary between people and societies. However, it would not be correct to say that social customs can determine if a particular character trait it is indeed a virtue, and this is because virtues emanate from what it means to be a human being [39]. Virtue ethics is undoubtedly an important aspect when we unpack the theory of ethics in its various guises because it lies at the heart of most ethics theories.

A true leader promotes good governance, policies, management practices, and a range of interpersonal relationships which demonstrate respect for the values and sensitivities of all stakeholders [9]. A true leader in especially and African context is a paradox in action. He or she needs to learn to tread cautiously between being a follower, a leader and a servant leader. The African leader of today is called upon to make a paradigm shift which consists of accepting and dealing with complex issues within the traditional spirit of Ubuntu in a time of global turbulence [12]. Nonetheless the leader should not become the slave of tradition or even their senses. Since Ubuntu conforms with moral choices which are forged on universal maxims, it is the ideal moral law for Africa which will inevitably allow sustainability to be promoted for future generations to succeed.

Considered from a utilitarian perspective, the leader must assess the cost and also the benefits of their intended actions on the triple bottom line, while when viewed deontologically, they need to consider the fundamental norms of society that must be observed. Thus, before they decide on any course of action, they need accurate information and insights and must take time and effort and be willing to act ethically and embrace personally held values in their organisational context [53].

Personally-held values, such as integrity, honesty and caring, are important factors to consider in all and especially leadership appointments [29]. From an African perspective, it is encouraging to see young Y-generation (Millenials) leaders emerging across the continent and it is evident that future leaders will certainly have greater skills, education, knowledge and understanding than many of the past and present. Millennials (those born between 1981 to 2000) comprise up 60 percent of the workforce in some organisations. As they take on different types of leadership roles in business, they will hopefully make a difference to ethical leadership but the evidence suggests a status quo situation in ethical approaches.

The Ethics Resource Center (ERC), a nonprofit organization dedicated to the development of high ethical standards and practices in public and private organizations, conducted a study referred to as "Generational Differences in Workplace Ethics". The research study examined the differences in attitudes toward ethical issues among four generational groups namely Traditionalists, Baby Boomers, Generation X and Millennials (or Generation Y). Sadly, the study showed that the youngest workers were more likely than preceding generations to feel the pressure from others to break ethical rules. This finding highlights the importance of organisations focusing on issues directly related to ethical culture 
during the orientation of new employees, so as to empower them feel more comfortable within the culture of their new workplace [54].

An additional outcome of the study was that younger workers reported more ethical misconduct in the workplace than their older colleagues, and this was despite the fact that they observed for example, far less examples of using company time to conduct personal business than older generations. Previous studies had shown that younger workers are less likely to manifest unethical behaviour, but this report exposed that they are now on the same level as many of their older counterparts when it comes to unethical conduct propensity.

The modern leader seeks the ability to influence rather than coerce those under their charge [23]. Leader behaviour often tends to ignore, disregard, or simply reinforce corrupt practices in their organisations and this is a key contributor to institutionalizing corruption [51] and this is unacceptable. Leaders also need to develop expertise in using various styles such as the authoritative, democratic, relational, and coaching styles, as they strive to understand the limitations that a coercive and authoritarian style possesses [45] [47].

There are daily accounts of various prominent leaders who at some point have enjoyed the trust of society and who have made unethical choices that are symptomatic of their willingness to abuse their positions of authority. While it may be true that unethical actions on the part of especially leaders, are rampant across the globe, such practices manifesting in African peoples have been influenced by the unfortunate immediate milieu that defines their existence and the manner in which they relate to one another [15]. There are paradoxes in Africa, when it comes to the fundamental principles and ethics that energise the selection of decisions with potential to make a great impact, be it positive or negative in society. Good ethical leaders exhibiting a virtuous mind-set are few and far between [23]. Consequently, when an organization finds a virtuous leader, it needs to invest in that leader for the benefit of the organization and society at large.

While ethical practices are important, there are continually reports of leadership failure in organizations which has increasingly led to character-driven leadership styles [55]. Studies show that for the successful implementation of any ethics or other strategy to succeed, the competence of the organisational leader must be first-rate [56].

“...African leadership styles and organisational ethics are also influenced by the available resources and the utilisation, in most cases by a few, while cautiously adapting to the forces of externalities who see ethics fail to solve the African leadership crisis and problems of corruption" [15].

Virtue has escaped from the mindsets of many in authority. We are led to believe that leaders cannot be reliably trusted to play their roles unless there is strict monitoring control of their actions, and firm adherence to regulatory frameworks. Virtue is in essence related to prosperity, positive energy, a meaningful life purpose and ennoblement [57]. Leaders are often subjected to chal- 
lenging moral dilemmas when they are presented with situations in which they feel a need to adhere to various actions and unethical decisions with which they would normally not be associated with [58]. The leaders that possess integrity are generally focused and resolute in their approaches, and are always attentive to being unswerving when it comes to making ethical decisions and choices. Corrupt leaders lack the courage to do the right things in difficult and challenging situations, and provide a poor example of desired behaviour for others to emulate. A leader that is effective will not take a laissez-faire approach when it comes to ethical conduct because such an approach or simply not support sustainability. High performance organizations irrespective of whether they are in the public or private sectors, are led by people who take a coordinated approach to implementing effective codes of conduct and who apply carefully crafted interventions and disciplines to combat corruption. The ethical leader promotes virtuous conduct by having ethics as an agenda point for every meeting and by tracking the progress of desired conduct and core values in all hierarchical levels. For many leaders, ethics is only spoken of at senior levels, but this is an error as it is important to cascade desired behaviours down to each level of the organization. This is very important especially currently, at a time when trust in leaders has been corroded and has arrived at an all-time low. It is concerning that Sub-Saharan Africa is the lowest scoring region on the Transparency International Corruption index, and the area has failed to translate its anti-corruption commitments into any meaningful progress. A region with blatant political and socio-economic contrasts and enduring challenges, many of the countries tussle with ineffective institutions and weak democratic values, which threaten anticorruption efforts [59].

\section{Organizational Culture and Cultural Dimensions}

Jean-Paul Sartre states that we are by definition morally bound because we share the planet with others whom we need to consider in the choices we make [60]. The primary paradigm of evaluation is always the self in relation to others. We should basically always be acting on the behalf of the interests of others [61], but sadly do not do so. Giberson, et al. [30] define the notion of organisational culture as "a collective phenomenon emerging from members' beliefs and social interactions, containing shared values, mutual understandings, and patterns of beliefs and behaviours that tie individuals in an organization together over time". There is no doubting the notion that the moral tone of an organisationis established by the leader. It is the leader then, who defines the code of ethics of the organisation to enable employees to be cognizant of the acceptable parameters to work within. Leaders need to strategise to improve the organisational culture to embrace ethical behaviour since it is the culture, which ultimately determines the state of ethics that exists. If the culture is not amenable to ethical actions, it will be futile to attempt to improve ethical action [62]. Groenewald [63] maintains that leadership is the most significant dependent variable to determine the 
state of ethics in a company.

An organizations ethical culture should improve ethical behaviour as it promotes aspects such as integrity, trust and moral conduct. All the members of any organization need to be well versed in its ethical position and effusively support it [64].

However, it is the leaders' role-model behaviour which is of paramount importance in inculcating the desired workplace culture [65]. We also need to carefully consider how cultures differ in the work environment. While Hofstede's Cultural Dimensions is a useful model to help in the understanding of different cultures, the more current work of Trompenaars and Hampden-Turner [66] is also highly valuable to consider in amplifying and also describing diverse cultural behaviours that African and indeed all leaders should be aware of. The ethical climate in ethically responsive organisations exudes care [67] and manifests in employee actions as it guides them in inculcating desired norms [68].

Trompenaars and Hampden-Turner [66] stress that especially the universalist versus the particularist approach is worth noting when it comes to what is deemed to be good and correct. In a universalist approach, rules are applicable in all contexts while in the particularistic approach, one's obligations and relationships with stakeholders is of paramount consideration. The individualistic approach posits that individuals are an important focal point since they contribute to a community as and when they like, whereas the communitarian perspective views the rights of a collective as being more important than those of any individual. This is where leaders are expected to become somewhat transformational in orientation as they strive towards communitarianism [66]. Organisational values perpetually divulge an organization's culture [22] and thus require careful consideration on an ongoing basis.

There are also aspects such as an emotional approach or one of neutrality. People also view status differently in different cultures so that in some people tend to believe that you are what you do, and they base a leader's worth according to what is done by the leader. These cultures value performance, no matter who you are whereas in others power, title, and position matter the most and one's role defines behaviour. In the western paradigm as in some others, people generally like events to happen in some kind of sequence or order. They place a high value on punctuality, adhering to plans and sticking to schedules. In African cultures however, people see the past, present, and future as essentially intertwined periods. They may thus often work on several tasks at once, and view any plans and commitments as being flexible. Specific versus diffuse or how far people get involved is also an important aspect to be considered. In some cultures' people keep work and personal lives separate while in others people see an overlap between their work and personal life [66]. There is in addition a difference between internal direction as opposed to outer direction and how people relate to their situation.

In some cultures' people believe that they can control their environment and 
even nature to realize their goals. This embraces how they work with other role-players and within organizations. Then there are those who believe that nature, or their environment, controls them so they are obliged to work with their environment to achieve their goals. Thus, whether at work or in relationships, they will focus their actions on other stakeholders, and avoid conflict where this is possible. Such leaders often need to be reassured that they are doing a good job [66].

\section{Corruption}

Corruption and poor governance are the primary origin for the increasing underdevelopment in Africa [69]. We should however note that while poor governance limits economic growth, a lack of economic growth causes instability to rise and this then leads to poor governance [70]. It should also be noted that in the western neo-colonialist understanding of "corruption" there is disagreement as to the causes of social and economic demise, so that corruption is not necessarily the main cause [71]. Some researchers such as Khan [72], disagree with the notion that corruption compromises economic development at all. Nonetheless corruption exists and the World Bank asserts that growth in Africa can only be driven by increases in private investment in countries that are free of corruption [73]. Good leaders are thus needed to bridge the divide between the past and to an extent the present, and the forging of a future ethical climate is vital, but economic growth is an imperative and this can only happen if efforts are made to change the culture so that prevailing practices and beliefs are modified [70].

When viewed globally, very little has been achieved in the fight to reduce corruption. If we look at the Transparency International Corruption Index from 1992 to the current time, it is apparent that with a few exceptions, the countries at the bottom of the list, for example Somalia, Sudan, Burundi, Afghanistan and Myanmar, always inhabit that space. Others such as Finland, Norway, Singapore, New Zealand and Denmark are usually amongst the top five least corrupt nations.

How has it become possible there and African culture which espouses Ubuntu tolerates unethical business practice? Clearly, what is a story of philosophy of goodness has been hijacked by greed and corruption emanating from western practices while western ethics itself frowns on corruption and bribery and there are nonetheless still many individuals and organizations which opt to go for the easy way out, bribing their way through deals and corrupting otherwise ethical people. Corruption exists where there is undue influencing of outcomes and an abuse of power for personal gain in a material fashion, or for opportunities, services and even sexual favours. Together with crime, corruption is certainly a very serious challenge facing South Africa. Corruption in leadership practice is undoubtedly a worldwide cause of distress. Leadership quality is a critical factor when it comes to the issue of whether or not an organization will be successful or not, irrespective if it be located in either the private or public domains. Once 
leadership is crooked this perpetually results in serious damage and public confidence in the organization is greatly diminished. Treviño [74], states that corruption is linked to a locus of control. There are however researchers such as Giacalone and Knouse [75], who view corruption as a Machiavellian "end justifies the means" tool. There are many other researchers and analysts who show us that corruption in any shape or form is highly destructive and a 'slap in the face' of justice. Very little has been achieved by African countries in the fight to reduce corruption.

Corruption permeates every corner of society, and unless we take significant action to prevent it, our national development on the whole will be severely impeded. Corruption which flies in the face of Ubuntu, is detectable, even if it is not that easy to uncover. In our society, we see corruption in public and private sectors and particularly in how we proceed against alleged criminals emanating from high office. It is evident in the manner in which important legal documents may disappear and in a range of exchanges in public and private settings.

Corruption has a myriad of manifestations that include inter-alia theft, graft, bribery, lying, misappropriation, embezzlement and even extortion and it reflects limited cognitive moral development [76]. Whatever form it takes it tends to reduce the credibility of the organization when especially leaders abuse their positions of power for personal advantage. Corruption injures all and sundry who are contingent on the integrity of the leader involved in it. Clearly when corruption succeeds in the public sector, resources that should be accessible for the community and national development are diverted, and issues such as poverty, unemployment, transformation and inequality are not addressed.

\section{Impacts of Corruption}

Corruption by its corrosive nature, makes people highly cynical and despondent. Even though some leaders try to minimize the negative impacts of corruption, it has many downsides. In Africa, many nations have rigid traditional highly structured bureaucratic systems which endorse corruption. Nonetheless, corrupt practices fly in the face of ubuntu as they generally undermine the moral fibre of society and each time there is nepotism, bribery, tenderpreneurism, abuse of power, embezzlement or theft, or suchlike, the erosion of morality deepens. No studies were found which consider the macro impacts of corruption in Africa, but there are sector reports. While macro costs are not measured, it is estimated that these run into billions of dollars. Matters are exacerbated as trade relationships become infected with both short and long-term negative impacts. Conversely, where corruption is lessened, countries are making incremental gains in their trade relations [77]. Thus, countries are most trusted on perceptions of corruption. Countries with poor governance structures and ineffective legal systems tend to get far less investment and thus scant benefit from each dollar that is invested in them so that the poor suffer the most. There is a direct correlation between the most visibly corrupt economies and the poorest economies [77]. 
Corruption undermines development and has huge economic costs in which some leaders obtain distorted incentives. The social costs are high as there is injustice and inequity in societies which are led by leaders who thrive on unprincipled behaviour and graft. When the corrupt leader is a politician this undermines popular rule and very often insurrections result. When leaders use their positions to gain what is clearly an unfair advantage, especially for themselves and also for their cronies, they undermine public trust and sow discord in society. Many election campaign leadership contenders make corruption a number one priority, but when they assume power the status quo remains. The unethical behaviours of leaders are the paramount factor connected with unethical decision making by others who serve under them [78]. In some cultures, corruption "oils the wheels" but it inevitably leads to suspicion. It is infused in some societies and exists in most to varying degrees.

Anand et al. [79] assert that tireless corruption is leading to widespread suspicions relating to public officials, and If purport to be genuinely concerned about the plight of the poor and disadvantaged elements in society, we should take corruption very seriously [80]. In both the private and public sectors, where there is corruption it is evident that organizational and national development is stifled. Powerful global investors think twice before conducting business with those suspected of or accused of corruption. Corruption in business and government adversely affects a nation and it results in an escalating role for all crime-fighting bodies as criminal activity also tends to increase. The misappropriation of assets by senior employees and especially fraudulent financial reporting by those in leadership have devastating effects on any organisation and especially felt is financial loss. Invariably public trust is eroded in the leader and the morale of a nation or business can be shattered with devastating spinoffs. Bribery and corruption are immense obstacles to development in many ways. That is why a strong ethical approach is needed to infuse an organisation [81] and deliver desired behaviours.

A continuous sequence of corruption fuels social inequality and leads to disillusioned people globally, who then turn as a last resort to populist politicians. The problem is that populist leaders are likely to be the most corrupt based on trends. José Ugaz of Transparency International states: "In countries with populist or autocratic leaders, we often see democracies in decline and a disturbing pattern of attempts to crack down on civil society, limit press freedom, and weaken the independence of the judiciary... Instead of tackling crony capitalism, those leaders usually install even worse forms of corrupt systems" [82]. It is suggested that corrupt leaders are attempting to gain a favorable impression by being unethical in practice [83] when they should be seeking to positively influence the nature and outcomes of their organisational actions throughout the hierarchy. Transparency is foreseen as a deterrent to corruption as it expands the possibilities for public or societal accountability, "that is, for citizens and citizens' associations to monitor, scrutinize, and act to hold public office holders to 
account" [84].

\section{Leadership Anti-Corruption Strategies}

Are ethical leaders born or made? Research informs us that less than thirty percent of leaders are genetically endowed to lead. Research studies in the public and private sectors as well as SMMEs and unionised and non-unionised workplaces evaluated the effects of leadership training. The astounding finding was that leadership can be taught in academic workshops of only a single day. We thus tend to overestimate what it takes to teach effective leadership skills and desired behaviours [77]. There is a considerable overestimation of what excellent leadership should comprise. Organizations tend to do very little to inspire employees to make a meaningful impact.

We should be very wary of training people to lead after they become a leader. Unfortunately, many organizations are risk averse and thus hesitant to devote time and money for training to leaders who need it the most [77].

An organisation's leader's principal goal should be to cater to the interests of all relevant stakeholders [50] while normatively reflecting on their actions and seriously contemplating their affiliation with society-at-large. The good leader does not try to be socially obstructive by seeking operating avenues which are devoid of regulation. He or she seeks to prioritize all stakeholder interests while complying with legislation and paying careful attention to the obligations, commitments and responsibilities of the role they are in as they shape ethics in the organization and promote sustainable development as part of a social contract [43].

The commonly found values espoused by unethical leaders such as material gain at all costs, inefficiency, and illogical thought, have dominated the media and made way to caring and empathy. Only by the addition of virtues and values into the leadership role, can the root causes of ethical leadership challenges be dealt with. Integrity in a leader's strategy is correlated to an ethical management approach. Various factors such as a lack of ethical behavioural standards and also individual ethical behaviour differences are responsible for unethical practices [85]. The reputation and public image of an organisation are greatly impacted upon by unethical actions [86].

Dose [87] advises andargues that in some organisations ethics includes both principles and work predilections and that "some values (and their subsequent decisions) have moral considerations while others are merely preferences without moral implications". It has also been established that culture has been found to be directly correlated with superior performance which raises the level of performance sustainability, promotes greater levels of trust and enhanced stakeholder engagement [88].

Vargas-Hernández, de León-Arias, Valdez-Zepeda and Castillo-Girón [26] assert that a carefully crafted integrity strategy necessitates that ethical practice should be what drives all organisations. Thus, the leader's integrity and related 
role-modelling actions influence the strategic direction of the organisation, bolster ethics consciousness and help fight corruption. In any event, when employees embraceprinciples such as integrity and honesty and see leaders act without integrity, they may perhaps experience significant personal conflict and lose faith in their organisation with serious consequences [89]. Leaders should be driving an integrity strategy by communication with stakeholders and by presenting them with guiding values and assurances of a desire to do the right thing. The South African government launched an enterprising notion termed Batho Pele in 2015, meaning "people first". This was intended to support initiatives to develop integrity in public administration through careful checking of officials' performance and compliance relating to ethical conduct. Raga and Taylor [90] contended that such policies are unlikely to be effective and that intense ethical training is more suitable. Leaders must demonstrate an authentic desire to be being committed, dependable, and willing to take action on the ethics they promote and have a broad enough repertoire to be able to deal with diverse teams. Furthermore, such values should be sustained by processes and systems that are conducive to ethical action and which support effective ethical leadership, possessing the relevant skills and the aptitude to make the needed ethical decisions. A good leader requires hierarchy, but should use it to construct useful bureaucracy and create suitable conditions for others to serve the organisation ethically. Leaders need to be honest and avoid polarization as this impedes effective operation [91]. Leaders must be bridge builders who serve with integrity and are functional and skilled in what they do and not compromise their organisation or other stakeholders. They need to drive their team of employees to achieve the objectives of the organisation ethically.

Leaders need to be able to get the results required by asking questions on how they were attained. Organisational ethics is then chiefly driven by the actions of its leaders and not by policies and codes of conduct. If organisational members see a leader being mendacious and deceitful in their dealings, then they might begin to believe that they can behave in a similar manner [91].

Greater transparency and oversight of leadership roles, and the eradication of opportunities for corruption are needed. Transparency coupled with a genuine desire for openness are essential on the part of the leader and serve to restrain corruption as one is held accountable for their actions. Transparency is attained by stakeholders observing, analysing, and taking necessary actions to hold leaders accountable [84]. It is equally critical to focus on identifying, nurturing and carefully developing potential leaders, long before they assume positions in organizations. The bottom line is that organizations want a return on investment but the converse is proved to be true in current literature. Many organizations fear training leaders who may opt to leave their service and become a competitors' weapon against them. What is fundamentally more significant is to ask the question what will likely happen if an undeveloped or poorly developed employee stays on in the organizations service? [77]. 
An organisation's culture influences a great deal of things in the organisation both from and operational and also a strategic perspective. This is why organisational culture must be carefully created [31]. Where an organisation has adopted an ethically oriented culture this supports employees to do their work efficiently and effectively [92].

It has also been ascertained that more judiciously considered forms of organization and governance structures which circumvent centralization of authority and power and which tend to balance authority across diverse organizational representatives, is indeed successful in reducing corruption [93]. There are also various other approaches. Peiffer and Alvarez [94] contend that, numerous anticorruption initiatives' seek to inspire stakeholders to call for improved control over rampant corruption. The UN, the World Bank and National anticorruption institutions advance the notion of a multipronged strategy as a vital approach to anticorruption efforts. The prevention of corruption, ethics education and effective law enforcement are considered to be equally important mechanisms which will contribute to expansively addressing corruption [95].

Ghoshal asserts that education is an important factor that requires greater consideration when it comes to ethics, "By propagating ideologically inspired amoral theories, business schools have actively freed their students from any sense of moral responsibility" [96]. The education leaders receive forges the intellectual and normative order of decision making as to what is morally right and wrong. Ethics education which includes a sound philosophical underpinning and the formulation of moral rules derived from assessing right action in case studies that have direct implications for a leader's actions should be in greater evidence in leadership schools.

The forging of an ethical organisation and the attainment of desirable ethical standing are significant accomplishments. However, the task of maintaining an ethical culture overshadows them, since the preservation of the status quo is an ongoing task. To realise the perfect situation necessitates that organisations adopt a strategy based proactivity, and a visible regular management of ethics [97]. We should also note that authentic leadership does not only comprise the leader's behaviors but also the characteristics of those who are led [28] and how their characteristics were forged. Authentic leaders develop over time and according to their cultural needs. They strive toward a future desired state of leadership excellence ability and with effort they get to attain this state and make a greater impact.

\section{Conclusions}

To come to the conclusion, it suffices to say that we need a logical break from passivity and inactivity on ethical practice to one of activity in dealing with notions of principles, and the judgement to discern right from wrong, what we should do, and what we ought to do. It is one thing for a leader to be creative and innovative and another to be logical, virtuous, and make appropriate res- 
ponses to ethical challenges which may manifest, and they do. Ethical considerations must mitigate self-serving behaviours and their catastrophic effects.

Corruption is a foremost barrier to Africa's social, economic, and human development. Is it likely that Noonan's prophecy will materialize and corruption will die? It cannot unless there is a concerted effort to fight it and effectively prosecute the guilty. We thus need exemplary African ethical leaders that are visionary and also willing and able to serve stakeholders as servants and who work tirelessly with the employees in the organization towards ethical goals. The emotional intelligence level of such a leader is derived from their experience relating to planning, organizing, monitoring and decision-making and is based on the notion of collective management and sound African traditions [18]. They are men and women who have been cultivated on ethical universal values and groomed for success in indigenous value systems [12] [18]. They are people whose life view is based on reflection and they evaluate and question their view while respecting those of others. They are virtuous ethicists and not moralists who believe their life view is superior and that they have all the answers. The virtuous leader wishes to contribute to society and considers the ecological impacts of what they are doing. They strive to work within existing laws, standards, frameworks and guidelines that always contribute positively to all the stakeholders and so effective governance and social responsibility are important to them. Yukl [48] articulates the notion that an organisations milieu should be planned to embolden open and honest communication in ethical issues. Employees and their leaders must be "on the same page" ethically speaking. Leadership is always troubled with ethical challenges and dilemmas so that a higher sense of moral development is required. When organisational values are not balanced with ostensibly ethical outcomes problems arise and leaders may be overwhelmed by pressure based on egotistical desires, greed and narcissism, to indulge in unethical and corruptive behaviours. Corruption is only preventable if the core values of an organization are vigorously the promoted and grounded on sound employment and legal practices [43]. It is the leaders task to define the desired culture which will be needed to enable an ethical strategy to be applied all processes and systems. This is where it is important to refine the criteria for recruiting new employees so as to make certain that there is a good employee organisation fit. Leaders need to put processes in place that make individuals are accountable for their actions while simultaneously empowering those in leadership roles and lower levels to enforce desired behaviours.

It is clear from the aforesaid that all public and private sector organisations need to regularly appraise their ethical climate and efforts to achieve their desired missions and visions. Where there are clear shortfalls and breaches in ethical conduct, they should contrive relevant ethics training interventions and modify business processes and systems so as reinforce ethics. I doing so, they also invariably promote sustainability and gain greater support from all stakeholders within the micro, meso and macro environments in which they operate. 
Having said this, the design of the organization is also important since by increasing the span of control and minimising the layers and size of management positions, the likelihood of ethical action becomes far greater. Middle managers and those in supervisory roles must be able to drive impact and engagement relating to ethical practices. Serving in leadership roles must be aligned in a structure which carefully reflects the strategic emphasis of the organization [65].

The roles and responsibilities of all employees in the organization should effectively by empowering enough to translate organisational strategy into an efficient and effective human resource strategy. When employees are disengaged in what they do, and are disenchanted with their employment, they seek easy ways to make money. This is exacerbated by a perception that the leader is corrupt so why should they care at all then. If leaders' allow employees to feel useful and engaged, this reduces the chances for corrupt activity to manifest. Jobs must be more relevant for employees and they should be in roles that allow them to satisfy their needs ethically using their skills productively and mitigating risks as regulations and codes of ethics are complied with. Organizations must be able to motivate and sustain transformation in what are increasingly turbulent environments. Transparency is a key to ethical leadership [98]. The core values should embrace the principles, which prohibit corrupt behaviour of in any shape or form. For this to happen it is important that all employees be fully aware of the desirable principles in their organization. This is why there is an urgent need for education, which places an augmented emphasis on rational ethics in leadership education, business education and also corporate training [99]. To mitigate against ethical dilemmas and challenges, leaders should be expected to attend obligatory, well organized and structured ethics education programmes [15].

Leadership skills and desired behaviours should be taught from primary school years onwards as this is the most impressionable period in one's life. Education is an essential anti-corruption component and should include informing stakeholders as to how corrupt activity impact's them. Only by the dissemination of such information can stakeholders get to understand their role in addressing and curbing corrupt practices. If future leaders are afforded an opportunity during their education, to comprehend the logic for overlapping ethical behaviour on their traditional organisational values they may reasonably circumvent the dangers of unethical practices. This is even more important when considering the role model function of a leader. Really effective leaders operate within each of the levels in their organisational matrices and model desired behaviours [100]. Leaders thus need to know about virtues, and the rudiments which encourage honesty and integrity since these represent a requisite part of any meaningful strategically guided long-term ethical leadership development. Leaders should "know thyself" as Aristotle stated, and which personal values they need to espouse as trustworthy and true leaders.

De George [101] maintains that trust and benevolence are tricky to uphold in any organisation. McMurrian and Matulich [102] state that organisations and 
leaders perceived to be operating under an ethical culture benefit from competitive advantages in areas such as stakeholder allegiance, employee efficiency, operational efficiency, public perceptions and also financially. Horner [103] proposes that if leaders create the right environment, which is one in which people want to be involved and feel devoted to their work, they will be in a strong position to influence and direct the activities of others. By contrast, where there has been a violation of trust in organisations by leaders, this could prompt articulation of great anger by personnel, and this is especially the case once trust has been formerly entrenched through all the levels of the organisation [81]. Ethical issues must be carefully chosen and transmitted in a way that enables approval, commitment and mainly understanding at all levels of the organisation. Leaders must make concerted efforts to make the right ethical decisions all the time irrespective of other issues [27]. The leader echelon is required to craft a code of ethics supported by experts and also all employees and such a code must contain unambiguous rules, be easy to understand, and unswerving when it comes to expected ethical behaviour.

A carefully promoted code of ethics that is inculcated on a regular basis, will generate a sustainable foundation for long-term archetypal leadership practices. Leaders must uphold and observe the principles that are rooted in the code of ethics and the constitution of the land, as they pursue the creation and sustenance of a culture of service quality excellence in their organisations based on leadership obligation, accountability, transparency, curbs on authority and especially integrity-all aimed at supporting the social or collective interests and duties and responsibilities towards others [104]. It is here where there is need for well-established and reinforced basic values at all levels within the organisation. Sustainable ethical behaviour is to an extent successfully derived logically from a sense of dependable virtue and an emphasis on a greater purpose in what an organisation sets out to accomplish. Stringent legal restrictions and harsh sentences for those involved in corruption will undoubtedly set the tone for ethical practice. Leaders should in any case not have any unrestricted power and their actions must be effectively monitored so as to prevent corruption raising its head.

Leaders' who are self-serving, need to transform themselves so that they can help others to transform. Given the scope of their authority and power, leaders should be influential and trusted, as they strive to incorporate the desired ethical values into all the processes, procedures and systems of their organization. The effective leader is a good role model when it comes to ethical action and virtue [36], and the values of their organisation must be transformed from being mere theoretical notions into a significant reality. Through the leader's guidance, ethical values should be cohesively incorporated into the strategic objectives of the organisation.

Thus, ethics education is sorely needed for especially those in leadership roles' as this will hopefully offer them a moral compass to empower them to make the 
correct judgments when facing vexing challenges and dilemmas. In the African context, such education cannot afford to omit the important intellectual aspects which exist in the many traditions and cultures of the African continent. African leaders should be cognisant of Western paradigms and leadership and management theory and practices, but should also adopt African practices that are dependable and which align with the diverse cultures in which they are in leadership roles. Consequently, efforts should be made to tap more into indigenous knowledge which may turn out to be better suited to the African setting in which leaders operate.

The altruistic value oriented leader African leader should desire a universalism and benevolence approach which clearly considers the welfare and interests of all stakeholders [105]. There is no need for pseudo leaders who seek to preserve their interests at all costs irrespective of collateral damage caused. When leaders are not achieving well in performance reviews they should not be retained as they will not achieve organisational goals. Leaders who abuse their power, lack of transparency, and operate in secret and are clearly corrupt endure in African and global society. Such generally unsuccessful leaders leave a trail of fruitless activity and devastation in their wake and they invariably possess egotistical goals and do not deliver what is required, to any of their constituents.

\section{Recommendations}

A socially responsive leader who is considered to be effective in a role, and also efficient, will meet its social responsibilities without squandering organisational resources. Such a leader will set ethics as the standard for right and wrong conduct, making policies far more efficient and the workplace more employee friendly and structured. This holds tremendous benefit for organisational leaders who benefit in a moral and practical sense. Whether an organization is in either private or public sector ethics goes beyond mere personal ethics and values with a good leadership and motivation and training it becomes a collective undertaking to know what is right or wrong and to do the right thing, and for morally appropriate standards be carefully maintained. Where there are systems in place and incentives based on extrinsic rewards, and/or compulsion based on threat of punishment for noncompliance, these may help, but it is better to ingrain an ethical mind-set that all those in the organisation buy into because it is the right thing to do. Where corruption is evident, effective legislation and disciplinary actions must be taken against the leaders who abuse their authority, influence and power. Where corruption is detected in some countries in Africa, the perpetrators are pardoned. This is where strong government is required with an anti-corruption stance.

The focus must be on decolonisation and radical transformation in how leaders lead. Western models are not necessarily suitable for the African leadership context. We have strong indigenous knowledge foundations that we should be tapping into more [18]. 
High performing future African leaders must be identified via vigorous data and comprehensive psychometric assessments and benchmarking with desired traits. When potential organisational leaders are interviewed for positions, they must be evaluated in their 360s according to the specifications for their possible role, and be likely to achieve desired organisational outputs without corrupt activity. This is where culture fit and even a soft-skills alignment are important to avoid a mismatch.

Above all, the African leader must fit the role of the organisation from an ethics perspective, and be developed and self-aware of their limitations and strive for excellence by focussing on strengths, weaknesses and opportunities. Talented ethical individuals' who are potential leaders, should be identified, nurtured and retained and finally afforded an opportunity to make a contribution that is meaningful in a corruption free environment. It is time to regenerate African leadership and move it beyond colonialist notions by taking Ubuntu and a sense of common humanity as our vantage point. We cannot do anything about the few bad apples in a barrel, but we can do something to keep the majority of good ones fresh and crisp, ethically speaking that is.

\section{Limitations of the Study}

Citing and referencing prior research studies could have been more exhaustive, time permitting, as this constitutes the basis of the study. While the theoretical foundations for the research question we investigated are solid, the scope of the research topic is huge, thus not all prior research studies that are relevant to the study were accessed.

\section{Conflicts of Interest}

The authors declare no conflicts of interest regarding the publication of this paper.

\section{References}

[1] Crane, A. and Matten, D. (2010) Business Ethics. Oxford University Press, Oxford, 233.

[2] Young, S. (2001) Keynote Speech-2001, Caux Conference, Switzerland, 14 July 2001.

[3] Killian, S. (2007) The ABC of Effective Leadership. A Practical Overview of Evidence Based Leadership Theory. Australian Leadership Development Centre, Melbourne.

http://www.leadershipdevelopment.edu.au/SiteMedia/w3svc674/Uploads/Documents/ Effective\%20Leadership\%20An\%20Overview\%20of\%20Leadership\%20Theory.pdf

[4] Schein, E.H. (1992) Organizational Culture and Leadership. 2nd Edition, Jossey-Bass, San Francisco.

[5] Menzel, D.C. (2003) Public Administration as a Profession: Where Do Body and Soul Reside? Public Integrity, 5, 239-249. https://doi.org/10.1080/15580989.2003.11770949

[6] Koslowski, P. (2010) The Philosophy of Management. In: Koslowski, Ed., Elements 
of a Philosophy of Management and Organization, Springer-Verlag, Berlin and Heidelberg, 7.

[7] Kandula, S.R. (2008) Strategic Human Resource Development. Prentice-Hall, Delhi.

[8] Deloitte LLP Ethics and Workplace Survey (2007). http://www.deloitte.com/view/en_US/us/press/PressReleases/8aa3cb51ed812210Vg nVCM100000ba42f00aRCRD.htm

[9] Bhindi, N. and Duignan, P. (1997) Leadership for a New Century: Authenticity, Intentionality, Spirituality and Sensibility. Educational Management and Administration, 25, 117-132. https://doi.org/10.1177/0263211X97252002

[10] Ericson, E.E. (1980) Solzhenitsyn: The Moral Vision. Eerdmans, Grand Rapids.

[11] Gyekye, K. (2010) African Ethics. In: Zalta, E.N., Ed., The Stanford Encyclopedia of Philosophy, Center for the Study of Language and Information, Stanford University, Stanford.

[12] Mafunisa, M.J. (2009) Ethics, African Societal Values and the Workplace. In: Nicolson, R., Ed., Persons in Community. African Ethics in a Global Culture, University of KwaZulu-Natal Press, Scottsville.

[13] Mafunisa, M.J. (2000) Public Service Ethics. Juta, Kenwyn.

[14] Shutte, A. (1993) Philosophy for Africa. UCT Press, Cape Town.

[15] Mathooko, J.M. (2013) Leadership and Organisational Ethics: The Three-Dimensional African Perspectives. 3rd Ethics, Human Rights and Medical Law Conference, Johannesburg, 7-9 May 2013.

[16] Mbigi, L. and Maree, J. (2005) Ubuntu. Knowres Publishing, Randburg.

[17] Mulemfo, M.M. (2000) Thabo Mbeki and the African Renaissance. Actua Press, Pretoria.

[18] Ramose, M. (2003) The Ethics of Ubuntu. In: Coetzee, P. and Roux, A., Eds., The African Philosophy Reader, Routledge, New York, 324-333.

[19] Yawson, R. (2017) Leadership Development in South Africa. In: Ardichvili, A. and Dirani, K., Eds., Leadership Development in Emerging Market Economies, Palgrave Macmillan, New York, 93-109. https://doi.org/10.1057/978-1-137-58003-0_6

[20] Nicolaides, A. (2016) Poverty Alleviation and Curbing Corruption in the South African Public Service. International Journal of Development and Sustainability, 5, 334-348.

[21] Van der Colff, L. (2003) Blueprint for Workplace Leadership in the 21st Century. Dictum Publishers, Gardenview, 36-37.

[22] O’Reilly, C.A. and Chatman, J.A. (1996) Culture as Social Control: Corporations, Cults, and Commitment, Research in Organizational Behavior, 18, 157-200.

[23] Van Rensburg, G. (2007) The Leadership Challenge in Africa. Van Schaik, Pretoria.

[24] OECD (Organisation for Economic Co-Operation and Development) (2010) OECD Economic Surveys. OECD, Paris.

[25] Wiredu, K. (2008) Social Philosophy in Post-Colonial Africa: Some Preliminaries Concerning Communalism and Communitarianism. South African Journal of Philosophy, 27, 322-339. https://doi.org/10.4314/sajpem.v27i4.31522

[26] José, G., Vargas-Hernández, J.G., de León-Arias, A., Valdez-Zepeda, A. and Castillo-Girón, V. (2012) Enhancing Leadership Integrity Effectiveness Strategy through the Institutionalization of an Organisational Management Integrity Capacity Systems. Journal of Knowledge Management, Economics and Information Technology, 2, 1-43. 
[27] Ejimabo, N.O. (2015) The Influence of Decision Making in Organisational Leadership and Management Activities. https://www.omicsgroup.org

[28] Luthans, F., Norman, S. and Hughes, L. (2006) Authentic Leadership: A New Approach for a New Time. In: Burke, R. and Cooper, C., Eds., Inspiring Leaders, Routledge, London, 84-104.

[29] Cameron, K.S., Bright, D.S. and Caza, A. (2004) Exploring the Relationships between Organizational Virtuousness and Performance. American Behavioral Scientist, 47, 766-790. https://doi.org/10.1177/0002764203260209

[30] Giberson, T., Resick, C. and Dickson, M. (2009) Leadership and Organizational Culture: Linking CEO Characteristics to Cultural Values. Journal of Business and Psychology, 24, 123-137. https://doi.org/10.1007/s10869-009-9109-1

[31] Sun, S. (2008) Organizational Culture and Its Themes. International Journal of Business Management, 3, 137-141. https://doi.org/10.5539/ijbm.v3n12p137

[32] Ochulor, C.L. and Okpo, O. (2010) The Place of Ethics in Business. A Case Study of Locke's Ethics. European Journal of Scientific Research, 44, 477-484.

[33] PSC (2006) State of the Public Service Report-Public Service Commission Report on the Code. http://www.psc.gov.za/documents/2007/state_of_the_public_service.pdf

[34] Van Aswegen, A.S. and Engelbrecht, A. (2009) The Relationship between Transformational Leadership, Integrity and an Ethical Climate in Organizations. South African Journal of Human Resource Management, 47, 1-9. https://doi.org/10.4102/sajhrm.v7i1.175

[35] Meads, D. (2017) Here's How Africa Can Take Advantage of the Fourth Industrial Revolution. World Economic Forum on Africa, Durban, 2 May 2017.

[36] Metz, T. (2007) Toward an African Moral Theory. Journal of Political Philosophy, 15, 332-341. https://doi.org/10.1111/j.1467-9760.2007.00280.x

[37] Shonhiwa, S. (2006) The Effective Cross-Cultural Manager-A Guide for Business Leaders in Africa. Struik Publishers, Cape Town.

[38] Ozar, D., Berg, J. and Werhane, P.H. (2000) Organisational Ethics in Healthcare: Toward a Model for Ethical Decision-Making by Provider Organizations. American Medical Association, Washington DC.

[39] Rachels, J. and Rachels, S. (2012) The Elements of Moral Philosophy. Seventh Edition, McGraw-Hill International Edition, New York.

[40] Kraut, R. (1989) Aristotle on the Human Good. Princeton University Press, Princeton.

[41] Azuka, E.B. (2009) Ethics of Leadership and the Integrity Question among Leaders. Life Psychologia, 17, 11-26. https://doi.org/10.4314/ifep.v17i1.43736

[42] Kithinji, F. (2013) Don't Push Workers; Try Pulling Them Instead (Management 101). Daily Nation, Jobs. 2013, 2 April 5.

[43] Waddock, S. (2007) Leadership Integrity in a Fractured Knowledge World. Academy of Management Learning and Education, 6, 543-547. https://doi.org/10.5465/amle.2007.27694954

[44] Seligman, M.S. (2002) Authentic Happiness. Free Press, New York.

[45] Forde, R., Hobby, R. and Lees, A. (2000) The Lessons of Leadership: A Comparison of Headteachers in UK Schools and Senior Executives in Private Enterprise. Hay GAO Performance and Accountability Report, London.

[46] Moore, M.H. (1976) Realms of Obligation and Virtue. Public Duties: The Moral 
Obligations of Government Officials. Harvard University Press, Cambridge.

[47] Goleman, D. (2000) Leadership That Gets Results. Harvard Business Review, 78, 78-90.

[48] Yukl, G., Mahsud, R., Hassan, S. and Prussia, G.E. (2013) An Improved Measure of Ethical Leadership. Journal of Leadership and Organizational Studies, 20, 38-48. https://doi.org/10.1177/1548051811429352

[49] Yukl, G. (2013) Leading in Organizations. 8th Edition, Pearson Education, Boston.

[50] Gichure, C. (2008) Ethics for Africa Today. An Introduction to Business Ethics. Paulines Publications Africa, Nairobi.

[51] Ashforth, B. and Anand, V. (2003) The Normalization of Corruption in Organizations. In: Kramer, R.M. and Staw, B.M., Eds., Research in Organizational Behavior, Vol. 25, Elsevier, Amsterdam, 1-52. https://doi.org/10.1016/S0191-3085(03)25001-2

[52] Grojean, M.W., Resick, C.J., Dickson, M.W. and Smith, D.B. (2004) Leaders, Values, and Organizational Climate: Examining Leadership Strategies for Establishing an Organizational Climate Regarding Ethics. Journal of Business Ethics, 55, 223-241. https://doi.org/10.1007/s10551-004-1275-5

[53] Pearce, C.L., Waldman, D. and Csikszentmihalyi, M. (2006) Virtuous Leadership: A Theoretical Model and Research Agenda. Journal of Management, Spirituality and Religion, 3, 60-77. https://doi.org/10.1080/14766080609518611

[54] Global Young Voices (2016) Are Millennials More Ethical Leaders in Business? December 17, 2016.

http://www.globalyoungvoices.com/fast-news-blog/2016/12/13/are-millennials-mor e-ethical-leaders-in-business

[55] Butts, J.B. (2012) Ethics in Organizations and Leadership. In: Butts, J.B. and Rich, K.L., Eds., Nursing Ethics: Across the Curriculum and into Practice, 3rd Edition, Jones and Bartlett, Boston, Chapter 12. http://www.jblearning.com/samples/0763749761/EthicalLeaderhip.pdf

[56] Meldrum, M. and Atkinson, S. (1998) Meta-Abilities and the Implementation of Strategy. Journal of Management Development, 17, 564-575. https://doi.org/10.1108/02621719810228425

[57] Cameron, K.S. (2003) Positive Organizational Scholarship. Berrett-Koehler, San Francisco.

[58] Manz, C.C., Cameron, K.S., Manz, K.P. and Marx, R.D. (2006) A Special Issue: Values and Virtues in Organizations. Journal of Management Spirituality and Religion, 3, 104-122. https://doi.org/10.1080/14766080609518608

[59] Transparency International (2019) Corruption Perceptions Index 2018. https://www.transparency.org/whatwedo/publication/corruption_perceptions_inde $\underline{\mathrm{x} \_2018}$

[60] Sartre, J.P. (1960) Existentialism and Human Emotions. The Wisdom Library, New York.

[61] Gini, A. (1996) Ethics and Leadership. Academy of Leadership, Kellogg Leadership Studies Project Working Paper.

[62] Ho, M. (2011) Ethics Management for the Construction Industry: A Review of Ethical Decision-Making Literature. Engineering, Construction and Architectural Management, 18, 516-537. https://doi.org/10.1108/09699981111165194

[63] Groenewald, L. (2016) South African Business Ethics Survey 2016. The Ethics Institute, Pretoria.

[64] Chatman, J.A. (1991) Matching People and Organizations: Selection and Socializa- 
tion in Public Accounting Firms. Administrative Science Quarterly, 36, 459-484. https://doi.org/10.2307/2393204

[65] Sauser, W.I. and Sims, R.R. (2007) Fostering an Ethical Culture for Business: The Role of HR Managers. In: Sims, R.R., Ed., Human Resource Management. Contemporary Issues, Challenges and Opportunities, Information Age Publishing, Charlotte, 253-285.

[66] Trompenaars, F. and Hampden-Turner, C. (2002) 21 Leaders for the 21st Century. Capstone, London.

[67] Denison, D.R. (1996) What Is the Difference between Organizational Culture and Organizational Climate? A Native's Point of View on a Decade of Paradigm Wars. Academy of Management Review, 21, 619-654. https://doi.org/10.5465/amr.1996.9702100310

[68] Bartels, L.K. (1998) The Relationship between Ethical Climate and Ethical Problems within Human Resource Management. Journal of Business Ethics, 17, 799-804.

[69] Ayittey, G.B.N. (2005) Africa Unchained. Palgrave Macmillan, New York. https://doi.org/10.1007/978-1-137-12278-0

[70] Sachs, J.D. (2002) The End of Poverty. Penguin, New York.

[71] Della Porta, D. and Vannucci, A. (2005) The Moral (and Immoral) Costs of Corruption. In: von Alleman, U., Ed., Demensionen Politischer Korruption, Sonderheft der Politichen Vierteljahresschirft, VS Verlag für Sozialwissenschaften, Wiesbaden.

[72] Khan, M.H. (2002) Corruption and Governance in Early Capitalism: World Bank Strategies and Their Limitations. In: Pincus, J. and Winters, J., Eds., Reinventing the World Bank, Cornell University Press, Ithaca.

[73] Deininger, K. and Mpuga, P. (2005) Does Greater Accountability Improve the Quality of Public Service Delivery? Evidence from Uganda. World Development, 33, 171-191. https://doi.org/10.1016/j.worlddev.2004.09.002

[74] Treviño, L.K. (1986) Ethical Decision Making in Organizations: A Person-Situation Interactionist Model. Academy of Management Review, 11, 601-617. https://doi.org/10.5465/amr.1986.4306235

[75] Giacalone, R.A. and Knouse, S.B. (1990) Justifying Wrongful Employee Behavior: The Role of Personality in Organizational Sabotage. Journal of Business Ethics, 9, 55-61. https://doi.org/10.1007/BF00382564

[76] Kohlberg, L. (1969) Stage and Sequence: The Cognitive-Developmental Approach to Socialization. In: Goslin, D.A., Ed., Handbook of Socialization Theory and Research, Rand McNally, Chicago, 347-348.

[77] Klitgaard, R. (2010) Public Lecture-The Future of Corruption. Lee Kuan Yew School of Public Policy, Singapore.

[78] Brenner, S.N. and Molander, E.A. (1977) Is Ethics of Business Changing? Harvard Business Review, 55, 57-71.

[79] Anand, V., Manz, C.C. and Glick, W.H. (1998) An Organizational Memory Approach to Information Management. Academy of Management Review, 23, 796-809. https://doi.org/10.5465/amr.1998.1255639

[80] Kaufmmann, D. (2002) Rethinking Governance: Questioning from Theoretical Perspectives. The World Bank, Singapore.

[81] Williams, L.L. (2006) The Fair Factor in Matters of Trust. Nursing Administration Quarterly, 30, 30-37. https://doi.org/10.1097/00006216-200601000-00006

[82] Sile, A.W. (2017) These Are the World's Most Corrupt Countries. World News, 
CNBC Tuesday, 24 Jan 2017.

http://www.cnbc.com/2017/01/24/these-are-the-worlds-most-corrupt-countries.ht $\underline{\mathrm{ml}}$

[83] DePaulo, P.J., DePaulo, B.M., Tang, J. and Swaim, G. (1989) Lying and Detecting Lies in the Organization. In: Giacalone, R.A. and Rosenfeld, P., Eds., Impression Management in the Organization, Erlbaum, Hillsdale, 377-396.

[84] Bauhr, M. and Grimes, M. (2014) Indignation or Resignation: The Implications of Transparency for Societal Accountability. Governance, 27, 291-320. https://doi.org/10.1111/gove.12033

[85] Singer, M.S. (2000) Ethical and Fair Work Behaviour: A Normative-Empirical Dialogue Concerning Ethics and Justice. Journal of Business Ethics, 28, 187-209. https://doi.org/10.1023/A:1006299811213

[86] Leiva, R., Ferrero, I. and Caldero'n, R. (2016) Corporate Reputation in the BusinessEthics Field: Its Relation with Corporate Identity, Corporate Image, and Corporate Social Responsibility. Corporate Reputation Review, 19, 299-315. https://doi.org/10.1057/s41299-016-0008-x

[87] Dose, J.J. (1997) Work Values: An Integrative Framework and Illustrative Application to Organizational Socialization. Journal of Occupational and Organizational Psychology, 70, 219-240. https://doi.org/10.1111/j.2044-8325.1997.tb00645.x

[88] Houghton, E. (2016) A Duty to Care? Evidence of the Importance of Organisational Culture to Effective Governance and Leadership. CIPD, Dublin.

[89] Hewlin, P.F. (2003) And the Award for the Best Actor Goes to...: Facades of Conformity in Organizational Settings. Academy of Management Review, 28, 633-642. https://doi.org/10.5465/amr.2003.10899442

[90] Raga, K. and Taylor, D. (2005) Impact of Accountability and Ethics on Public Service Delivery: A South African Perspective. Public Manager, 34, 244-254.

[91] Porter, L. (2014) Take It from the Top: How Leaders Foster an Ethical Culture or Not.

http://associationsnow.com/2014/01/take-it-from-the-top-how-leaders-foster-an-et hical-culture-or-not/andgt

[92] Shahzad, F., Luqman, R.A., Khan, A.R. and Shabbir, L. (2012) Impact of Organizational Culture on Organizational Performance: An Overview. Interdisciplinary Journal of Contemporary Research in Business, 3, 975-985.

[93] Pearce, C.L., Manz, C.C. and Sims, H.P. (2008) The Roles of Vertical and Shared Leadership in Enactment of Executive Corruption: Implications for Research and Practice. The Leadership Quarterly, 19, 353-359. https://doi.org/10.1016/j.leaqua.2008.03.007

[94] Peiffer, C. and Alvarez, L. (2016) Who Will Be the "Principled-Principals"? Perceptions of Corruption and Willingness to Engage in Anticorruption Activism. Governance, 29, 351-369. https://doi.org/10.1111/gove.12172

[95] GAO US Government Accountability Office (2003) GAO Performance and Accountability Report, 2002. Management Consultants Ltd. http://www.gao.gov/products/GAO-03-305SP

[96] Ghoshal, S. (2005) Bad Management Theories Are Destroying Good Management Practices. Academy of Management Learning and Education, 4, 79-91. https://doi.org/10.5465/amle.2005.16132558

[97] Schoeman, C. (2012) An Ethics Strategy Is Essential to Create an Ethical Business. WITS Business School Journal, No. 31. 
[98] Gunn, B. (1995) The Paradigm Shift in University Management. International Journal of Educational Management, 9, 28-40. https://doi.org/10.1108/09513549510146584

[99] Simpson, R. (2006) Masculinity and Management Education: Feminizing the MBA. Academy of Management Learning and Education, 5, 182-193. https://doi.org/10.5465/amle.2006.21253782

[100] Pearce, C.L. and Sims, H.P. (2002) Vertical versus Shared Leadership as Predictors of the Effectiveness of Change Management Teams: An Examination of Aversive, Directive, Transactional, Transformational, and Empowering Leader Behaviours. Group Dynamics. Theory, Research, and Practice, 6, 172-197. https://doi.org/10.1037//1089-2699.6.2.172

[101] De George, R. (2005) A History of Business Ethics. Accountable Corporation, Santa Clara University, Markkula Center for Applied Ethics, Santa Clara. http://www.scu.edu/ethics/practicing/focusareas/business/conference/presentations /business-ethics-history.html

[102] McMurrian, R. and Matulich, E. (2006) Building Customer Value and Profitability with Business Ethics. Journal of Business and Economics Research, 4, 11-18. https://doi.org/10.19030/jber.v4i11.2710

[103] Horner, M. (1997) Leadership Theory. Past, Present and Future. Team Performance Management, 3, 270-287. https://doi.org/10.1108/13527599710195402

[104] Nkondo, G. (2007) Ubuntu as a Public Policy in South Africa: A Conceptual Framework. International Journal of African Renaissance Studies, 2, 88-100. https://doi.org/10.1080/18186870701384202

[105] Elliott, L. (2005) Transnational Environmental Harm, Inequity and the Cosmopolitan Response. In: Dauvergne, P., Ed., International Handbook of Global Environmental Politics, Edward Elgar, Cheltenham, 486-501. 